\title{
Discussion on Influences of Cloud Computing on Enterprise Informatization
}

\author{
Ye Xu \\ Shandong Foreign Trade Vocational College,266100 China
}

\begin{abstract}
Cloud computing as an emerging service model, has been widely applied in enterprise informatization.Cloud computing platform can provide hardware and software resources and services for enterprises users, effectively reducing the cost of enterprise informatization, and meeting the informatization needs of enterprises in different stages of development. In this paper, we analyze the situation of China's enterprise informatization, and then introduce the technical characteristics and application of cloud computing, from the perspective of evolution, infrastructure, services set and construction mode of cloud computing. At last, we summarize some influences of cloud computing on enterprise informatization.
\end{abstract}

Keywords- Cloud Computing; Informatization;Services Set; Construction Mode

\section{SITUATION OF CHINA'S ENTERPRISE INFORMATIZATION}

According to a recent survey, more than $30 \%$ of enterprises believed that information technology products and services do not fit the requirements of enterprises, while more than $20 \%$ of enterprises thought that the effect of information technology is not obvious. ERP is widely used in China's enterprises, but the effect is not good enough. According to statistics, China's enterprises have invested over 8 billion Yuan in the ERP system so far, $10 \%$ to $20 \%$ of which have achieved full implementation success, $30 \%$ to $40 \%$ partial success, and up to $50 \%$ failed. Thus, although many enterprises had put a lot effort in informatization, they failed to get the desired effect. By analyzing the relevant literature and survey report, we conclude some problems of China's enterprises informatizaiton, referred as Figure 1.

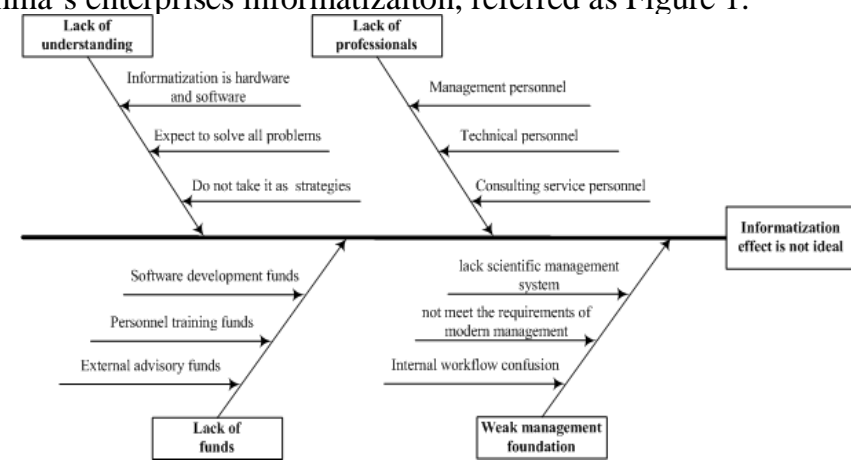

Figure 1.Enterprise Informatization Situation

\section{A. Lack of understanding of informatization}

Some enterprises still misunderstanding the informatization. On the one hand, they think that informatization is just the computer software and hardware configuration; on the other hand, they expect too much of the informatization, hope that application systemcan solve any problem within the enterprise. In addition, some leaders of enterprises lack of meaning and understanding of the importance of information technology. They do not consider the informatization from the perspective of corporate strategy, which results in non-ideal effect of informatization construction

\section{B. Lack ofinformatization construction funds}

Implementation of enterprise informatizationnot only needs input of computer, network equipment, transmission equipment and other hardware resources, but also needs software development platform, personnel training, external advisory, etc. It requires a lot of financial support, so enterprise informatization is a huge, costing project. However, many small and medium enterprises (SEM) are facing financing difficulties, and funds can be used for information construction is very limited.

\section{Lack of informatization professionals}

Informatization needscomplex professionals, who have both sophisticated technology and advanced management concepts, while these people normallyhave higher demands on enterprise scale, work environment and salary, that general business hard to meet their needs. Due to the lack of professional and technical personnel, enterprise information resources are not fully applied.

\section{Business management foundation is weak}

Informatization is closely related to the business process. If the business process management mode does not meet the requirements of modern management, the informatization will be difficult to carry out. Many enterprises lack scientific management system, with subjectivity and randomness.

\section{APPLICATION OF CLOUD COMPUTING TECHNOLOGY}

Cloud computing is further developmentand commercial implementation of distributed processing, parallel processing, grid computing, network storage and large data center. Cloud computing is to use information technology as a service through the network. People use cloud computing services like water and electricity, with only one input and output terminal. The service and data processing are all completed 
by network, and the users do not need to consider where these data and services are, only need to pay the fee to the operator in accordance with the flow and service. Operators are responsible for the maintenance of data center and server clusters, that is to say, the operators provide storage space, maintain the application and ensure information security.

\section{A. Evolution of Cloud Computing}

Cloud computing applications are concentrated on the Internet, which coincides with grid technology, utility computing. Cloud computing is not a new technology appearing suddenly, but an integration platformthatevolved from the grid computing. For enterprise users, value of cloud computing lies in the re-sort of the internal IT infrastructure.

The evolution of cloud computing has gone through about five stages, as shown in Figure 2.

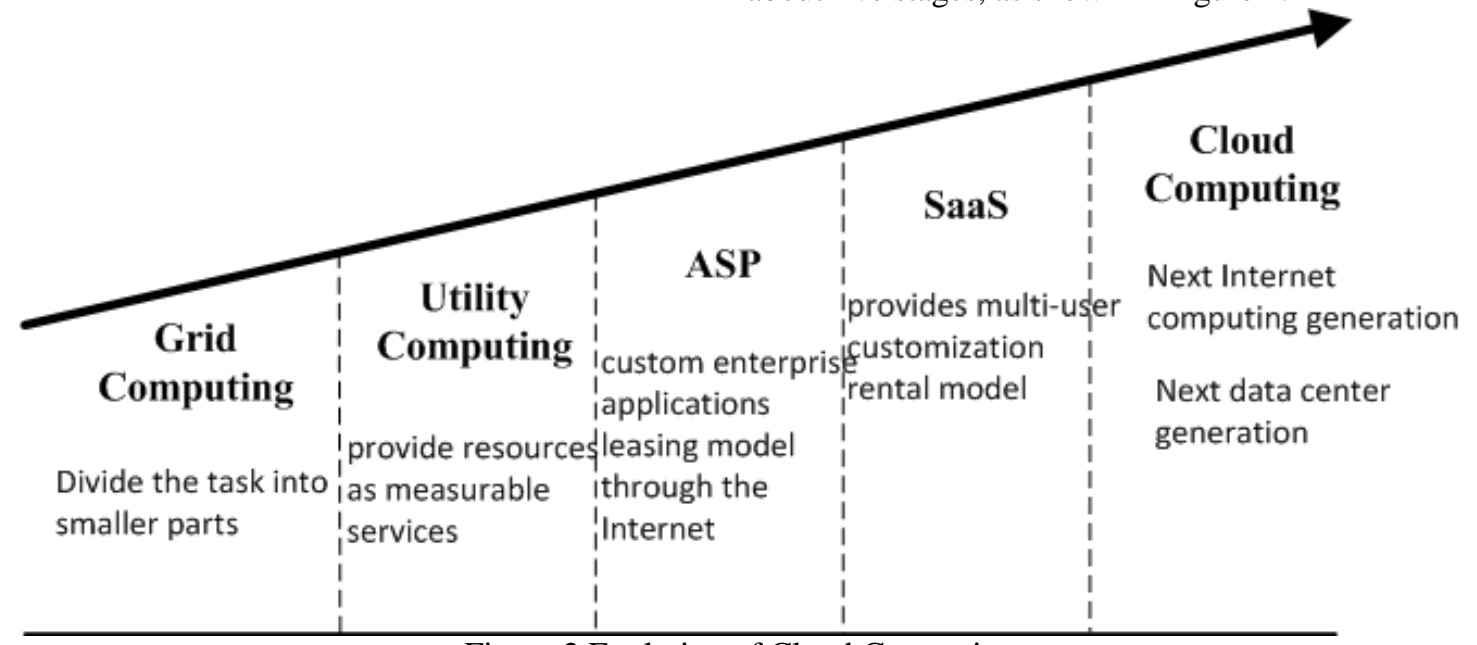

Figure 2.Evolution of Cloud Computing

(1) Grid computing. Divide the task that requires very great computing power to complete into smaller parts, and then assign these smaller tasks to many computers for processing. Finally,summarize these results to obtain final result.

(2) Utility Computing. It is to provide resources as measurable services. Utility Computing is a widespread IT infrastructure, which can transmitall computing needs. Enterprises can deploy far less than the current computing assets, but pay for IT services from utility computing architecture.

(3) Application service provider (ASP). It appeared in the late 1990s, a custom enterprise applications leasing model through the Internet.

(4) Software as a Service (SaaS). It was put forward in 2001, that software provides multi-user customizationrental model via the Internet.

(5) Cloud computing. As the development trend of nextgeneration data center, itwas first proposed in 2007. It is the development mode that provides IT resources to users as services via the Internet.

\section{B. Cloud Computing Infrastructure}

Cloud computing infrastructure can be divided into three categories:

(1) Public cloud. It is operated by a third party. Many servers, storage systems and other infrastructure are mixed together. Users don't know other users' information in the server, network and disk.

(2) Private Cloud. Owned by a single client, it provides infrastructure based on customer needs, including server, network and disk. This client can determine which users can access to infrastructure and applications and control where the applications run.

(3) Hybrid cloud. It units the public cloud and private cloud together. Customers partially own the cloud resources, and partially share the cloud resources with others.

\section{Cloud Computing Services Set}

Users hire any service in the cloud according to their needs. Virtual Technology applied in cloud computing divides it into three service sets as follows:

(1) Software as a Service (SaaS). Application is provided to users as a service. One instance of the application running on the cloud server can provide services to multiple users.

(2) Platform as a Service (PaaS). It is abstract package of development environment and load package of effective service. That is, take the development platform as a service, to achieve effective service load balancing.

(3) Infrastructure as a Service (IaaS). It is to take the basic storage and computing ability asstandard service to provide for users.

Almost all IT resources can be provided as a cloud service, such as applications, computing ability, storage capacity, network, programming tools, and even communication services and collaboration tools.

\section{Cloud Computing Information Construction Mode}

After a long period of accumulation of informatization, it has progressive developed the traditional information construction modes and network modes. In the development of the Internet today, newinformation construction modes emerge. From ASP to SaaS and then to cloud computing, it has entered a new stage of information construction mode development. 
Typical traditional information construction modes are customized development, outsourcing model and overall

introduction. Comparison of traditional mode and network mode is shown as Table 1 .

Table 1. Comparison of Traditional Mode and Network Mode

\begin{tabular}{|c|c|c|c|c|c|c|}
\hline \multirow[b]{2}{*}{ Item } & \multicolumn{3}{|c|}{ Traditional Mode } & \multicolumn{3}{|c|}{ Network Mode } \\
\hline & $\begin{array}{c}\text { Customized } \\
\text { Development }\end{array}$ & $\begin{array}{c}\text { Outsourcing } \\
\text { Model }\end{array}$ & $\begin{array}{c}\text { Overall } \\
\text { Introduction }\end{array}$ & ASP & SaaS & Cloud Computing \\
\hline $\begin{array}{c}\text { Deployment } \\
\text { Cost }\end{array}$ & very high & relatively high & very high & low & low & low \\
\hline $\begin{array}{c}\text { Development } \\
\text { Cycle }\end{array}$ & Long & Long & Long & $\begin{array}{c}\text { Relatively } \\
\text { short }\end{array}$ & Short & short \\
\hline Flexibility & high & Medium & Relatively low & relatively high & high & high \\
\hline $\begin{array}{c}\text { Maintenance } \\
\text { Costs }\end{array}$ & high & high & Medium & low & low & low \\
\hline Risk & high & high & Medium & low & low & low \\
\hline $\begin{array}{c}\text { Personalized } \\
\text { Level }\end{array}$ & high & Medium & Medium & Medium & $\begin{array}{c}\text { Medi } \\
\text { um }\end{array}$ & Medium \\
\hline Safety & Medium & high & high & Medium & $\begin{array}{c}\text { Medi } \\
\text { um }\end{array}$ & Medium \\
\hline Quality Level & Medium & high & high & high & high & high \\
\hline $\begin{array}{c}\text { Enterprise } \\
\text { Scale }\end{array}$ & Large & $\begin{array}{c}\text { Large and } \\
\text { medium }\end{array}$ & $\begin{array}{c}\text { small and } \\
\text { medium }\end{array}$ & $\begin{array}{c}\text { small and } \\
\text { medium }\end{array}$ & small & small and medium \\
\hline
\end{tabular}

III. INFLUENCE OF Cloud COMPUTING ON ENTERPRISE INFORMATIZATION

\section{A. ChangeInformation Construction Mode}

Before using cloud computing, generally enterprise commissioned developers to develop information systems for their own needs, and purchase servers and other hardware facilities, with software system deployed on their own servers. Since the emergence of cloud computing technology, enterprises can hire application services or infrastructure services, or both. Enterprises can determine theinformation construction modeaccording to their actual situation.

(1) Large enterprises currently have a lot of software and hardware resources. In order to make full use of these resources, enterprises can build their private clouds. As for the services thatbeyond the private cloud computing ability, enterprises can tend to public clouds.

(2) Information level of small and medium-sized enterprise is not high enough, with less software and hardware resources. In order to balance the information management and capital investment, these enterprises can move daily production applicationsto the cloud environment with lower cost, rather than spend a lot of money to build complex IT infrastructure within the company.

\section{B. Reduce Information ConstructionCost}

With the help of cloud computing technology, when enterprises construct information system, they can hire many infrastructure and software, without purchasing, to reduce information construction costs. Such mode of unified maintenance by cloud computing service providers makes it easier to upgrade the software at any time, to respond quickly to customer needs. The introduction of cloud computing technology does not require enterprises to hire system maintenance personnel, so that reduce the personnel costs and management costs.
C. Solve the Problem of Lack of Professionals

All enterprise software is running on the service provider side, and the service provider is responsible for maintaining. Enterprises don't need to hire new staff and technical advisers, just purely enjoy the service, eliminating the trouble of lack of technology and professionals. When users encounter problems using the software, they can notify ISP maintenance personnel to handle, without spending their energy and resources to solve them.

\section{Convertthe Way Users Work}

With the help of cloud computing technology,the user terminal may not need an operating system and a storage device, and the browser can manage to complete all the work. All data and documents are stored in the cloud computing. Users at any time and any place can log in to the computing cloud to complete their daily work, no longer confined within the company. Therefore, in the future, staffcan freely arrange their office location and work time, which change the mode of uniform time, unified location, greatly improving working efficiency.

\section{E. IncreaseReturn on Investment}

By using cloud services, many can change the status quo they prohibitive to network resources because of too muchIT capital spending. For growing enterprises, the return on data center investment is much low, and it is difficult to match the fast-growing business. Now, cloud computinghiring mode provides the right solution for these enterprises. Cloud mode allows enterprises to focus their time and energy on larger core business. Enterprise can be quickly promote their products to users through cloud computing platform and get more market opportunities, to achieve greater output and higher rate of return on investment.

\section{F. Improve the competitiveness of SMEs}

Cloud computing not only brings convenience to large enterprises, but also to bring tangible benefits for SMEs. Through cloud computing, the most powerful, the most advanced technology will not only owned by big enterprises, 
but also available for SEMs, and even cost less. With the development of business, enterprises can easily extend the computing and storage resources. The standardization services from cloud computing enable SEMs to have advanced management mode. Competing parties are in the same starting line in informatization, enterprises have more energy to promote innovation, greatly improving the competitiveness of SMEs.

\section{CONCLUSIONS}

Cloud computing as an emerging service model, has been widely applied in enterprise informatization.

\section{REFERENCES}

[1] K Li. Optimal load distribution in nondedicated heterogeneous cluster and grid computing environments[J]. Journal of Systems Architecture, 2008, 54:111-123.
[2] R.M.Luis, M. V. Luis, and V Gil et al. From Infrastructure Delivery to ServiceManagement in Clouds [J].Future Generation Computer systems, 2010, 26,1226-1240.

[3]Leena Jain, Sushil Bhardwaj. Enterprise Cloud Computing: KeyConsiderations for Adoption [J].International Journal of Engineering andInformation,2010(2).

[4] Godse M, Mulik S. An Approach for Selecting Software-as-aService(SaaS)Product [J].IEEE International Conference on cloud computing, 2009, 155-158.

[5] Han, S.-M. Efficient Service Recommendation System for Cloud ComputingMarket [J]. ACM International Conference Proceeding Series,2009(403),839-845.

[6] Z. S. Xu. Uncertain linguistic aggregation operators based approach tomultiple attribute group decision making under uncertain linguisticenvironment [J]. Information Sciences, 2004, 168, 171-184.

[7] X. B. Liu, F. Pei et al. An MAGDM approach combining numerical values withuncertain linguistic information and its application in evaluation of R\&Dprojects [J]. International Journal of Computational Intelligence Systems, 2010(3), 575-589. 